\title{
25 Research Square \\ Risk Factors for Surgical Site Infection in Head and Neck Cancer
}

chengwen gan

Hainan Provincial People's Hospital: Hainan General Hospital

yannan wang

Guangdong General Hospital: Guangdong Provincial People's Hospital

yan tang

Hunan University of Chinese Medicine

kai wang

Second Xiangya Hospital

bingcan sun

Second Xiangya Hospital

mengxue wang

Second Xiangya Hospital

Feiya Zhu ( 188102160@csu.edu.cn )

Second Xiangya Hospital https://orcid.org/0000-0003-0268-6336

\section{Research Article}

Keywords: Head and neck cancer, Surgical site infection, Diabetes mellitus, Tumor site, Flap failure, Preoperative radiotherapy

Posted Date: June 3rd, 2021

DOI: https://doi.org/10.21203/rs.3.rs-512387/v1

License: (c) (1) This work is licensed under a Creative Commons Attribution 4.0 International License. Read Full License

Version of Record: A version of this preprint was published at Supportive Care in Cancer on November 26th, 2021. See the published version at https://doi.org/10.1007/s00520-021-06687-8. 


\section{Abstract \\ Purpose}

Surgical site infection (SSI) frequently occurs in patients with head and neck cancer (HNC) after tumor resection and can lead to death in severe cases. Moreover, there is no definitive conclusion about the risk factors of SSI. Therefore, it is of great clinical significance to study the factors affecting the SSI.

\section{Methods}

The HNC patients included in this study were all from the Department of Oral and Maxillofacial Surgery of the Second Xiangya Hospital of Central South University (CSU), and these patients received surgical treatment in the department from January 2018 to December 2019. Univariate and multivariate regression analysis was applied to determine the risk factors of SSI. To identify the key risk factors of $\mathrm{SSI}$, the caret package was used to construct three different machine learning models to investigate important features involving 26 SSI-related risk factors.

\section{Results}

Participants were $632 \mathrm{HNC}$ patients who underwent surgery in our department from January 2018 to December 2019. During the postoperative period, 82 patients suffered from SSI and surgical site infection rate (SSIR) was about $12.97 \%$. Diabetes mellitus, tumor site (floor of mouth) and flap failure were consistently ranked the top three in the 26 SSI-related risk factors. In addition, SSI can increase postoperative hospital stays and flap failure rate.

\section{Conclusion}

Diabetes mellitus, tumor site (floor of mouth), flap failure, preoperative radiotherapy, neck dissection (bilateral) are risk factors for SSI of HNC.

\section{Background}

The frequency of surgical site infection (SSI) after head and neck cancer (HNC) surgery is high, especially in clean-contaminated surgery and major surgery [1]. Previous studies have shown that postoperative surgical site infection rate (SSIR) in HNC patients is about $8.1 \sim 45 \%[2-6]$. It remains high even when the adequate prophylactic antibiotic are used[7]. SSI may have an adverse prognosis, cause significant morbidity, flap necrosis, poor cosmetic results, delayed wound healing, prolonged hospitalization, and, sometimes, even death $[2,8]$. Meanwhile, SSI increases the mortality during the perioperative period. In our previous study we found that SSI is a risk factor for perioperative death of HNC and it is significantly correlated with poor overall survival (OS) of HNC patients[9]. 
Many risk factors of SSI have been reported in previous studies. Such as advanced age, diabetes, smoking, preoperative radiotherapy, prior surgery, preoperative chemotherapy, advanced American Society of Anesthesiologists (ASA) grade, low preoperative white blood cell (WBC) count, hypoalbuminemia, intraoperative blood transfusion, tracheotomy, contaminated wounds, lymph node metastasis and reconstruction with myocutaneousflaps or microvascular-free flaps, etc. [5, 7, 10-13]. However, due to the differences in study methodology, number of patients and sample size, there are still some disputes in different studies. For example, whether diabetes, tumor location or previous radiotherapy can be regarded as potential risk factors for SSI causes controversy $[5,14,15]$. Coskun, et.al. found diabetes mellitus, tumor location and history of prior radiotherapy were not associated statistically with wound infection in head and neck surgery (HNS) [16]. Sepehr, et al. found diabetes was not a risk factor for infection after HNS [17]. Similarly, Hitomi, et.al indicated that age, body mass index, smoking, diabetes, sex, previous radiotherapy or ASA score were not correlated with SSI [12]. However, Milap D. et.al showed HNC patients with diabetes have significantly greater rates of postoperative infections [18]. Margita, et.al indicated that gender, smoking, tumor localization and neck dissection were significantly related to the occurrence of wound infection [19]. So far, there is no clear definition of risk factors for SSI of HNC surgery.

In addition, these SSI study cohorts appear to be highly heterogenous if they included both head and neck surgical area and flap donor area infections. Therefore, in this study, we only focused on the SSI of head and neck incision after major surgery. Through this study, we found that 82/632 (12.97\%) patients suffer from SSI during postoperative period (from January 2018 to December 2019). Multivariate logistic regression analysis shows that diabetes mellitus, tumor site, preoperative radiotherapy, flap failure, neck dissection (bilateral) are risk factors for SSI of HNC. Through Machine Learning, for the first time, we found that diabetes mellitus, tumor site and flap failure were consistently ranked the top three in the 26 SSI-related risk factors. In addition, we also found that SSI increases the length of postoperative hospital stay and flap failure rate. Therefore, identifying these risk factors may help improve the perioperative care and management of HNC patients.

\section{Materials And Methods}

\section{Study design and samples}

A total of 632 consecutive patients underwent $\mathrm{HNC}$ major surgery with primary reconstruction at Department of Oral and Maxillofacial Surgery from January 2018 to December 2019. Surgical procedures include excision of the tumor, neck dissection, and flap reconstruction, if required. All head and neck wounds were categorized into Class I to Class IV according to the Centers for Disease Control (CDC) Surgical Wound Classification[13, 20]. The criterion for enrollment in this study were as follows: (1) More than one month of follow-up postoperatively without a loss. (2) Histologically confirmed diagnosis of head and neck malignant neoplasm. This study exclusively included Class I (clean) and Class II (cleancontaminated) wounds. Class III (contaminated) and Class IV (dirty-infected) wounds were excluded.

\section{Data collection methods}


The patients' data was collected and sorted from our hospital's electronic database, which contains prior medical records and postoperative follow-up information.

\section{Demographics and clinical data}

Data obtained from medical records included demographic distribution, pathology, clinical imaging, and treatment. A total of 26 putative risk factors were recorded in each patient and statistically analyzed to elucidate SSI related factors. For demographics and comorbidities, age, sex, status of smoking and alcohol drinking, diabetes, TNM stage and ASA grade were considered. Preoperative parameters included primary tumor site, history of radiotherapy and/or chemotherapy, preoperative WBC level, preoperative albumin level and tumor recurrence. Parameters during surgery consisted of concurrent neck dissection, mandibular surgery, reconstructive procedures, airway management, operation time, estimated blood loss $(E B L)$ and transfusion. The postoperative parameter of stage classification was ultimately determined based on the pathologic examination of the primary tumor and lymph nodes intraoperatively removed during the operation.

In this study, the definition of SSI is: (1) presence of purulent secretions from the incision or drain, (2) isolation of the infectious agent in the fluid found in the wound, (3) diagnosis of infection by the physician (The diagnosis was mostly based on the presence of erythema, tenderness, swelling, fever, or elevated WBC level) $[7,21]$. Preoperative laboratory test results of blood cell analyses were defined according to parameters issued by the Ministry of Health of China in 2012 as follows: WBC (normal:3.5$9.5 \times 10^{9}$ per l, low: $<3.5 \times 10^{9}$ per l, high: $>9.5 \times 10^{9}$ per l), albumin (normal:40-55 g/l, low: $<40 \mathrm{~g} / \mathrm{l}$, high: $>55$ $\mathrm{g} / \mathrm{l})$.

\section{Machine Learning}

To identify the key risk factors of SSI, we used the "caret" package to construct three different machine learning models to investigate features of importance involving 26 SSI-related risk factors. Neural network(nn), random forest(rf) and Gradient Boost Machinet(gbm) were used to rank the 26 risk factors by their status in two SSI states (positive and negative). The results were visualized by ggplot2 package.

\section{Statistical Analysis}

Statistical analyses were performed using SPSS 25.0 software (SPSS Inc., USA), and R, version 3.6.1 (R Foundation for Statistical Computing, Vienna, Austria). Pearson's chi-squared test or Mann-Whitney U test were used to determine whether there was a significant difference between each selected demographic or clinical factors and SSI. Multiple regression analysis was performed to reveal the relationship between SSI and demographic and clinical factors[22]. $P$ value $<0.05$ was considered statistically significant.

\section{Results}

\section{Demographic features of the patients.}


A total of 632 patients with a median age of 57 (from 24 to 92) have been enrolled in this study, including 493 males and 139 females. Among them, SSI was present in 82 patients (12.97\%). 126 patients had diabetes. 35 patients underwent preoperative radiotherapy. 22 patients received preoperative chemotherapy. Tumor recurrence occurred in 64 patients. Primary tumor sites were as follows: 265 in the tongue, 40 in the gingiva, 66 in the buccal, 80 in the floor of mouth, 42 in the jawbone, 22 in the lips, 40 in the palate, 35 in the retromolar region, 27 in submandibular, 9 in the oropharynx, and 6 in other areas. Clinical stages were as follows: I-II: 340, III-IV: 292. ASA grade: I-II: 342, III-IV: 290. For different neck dissections, selective neck dissection was performed in 373 patients, modified neck dissection in 45 patients, bilateral neck dissection in 47 patients, radical neck dissection in 43 patients, while neck dissection was not performed in 124 patients. Reconstructive procedures: free flap repair was performed in 421 patients, including: 340 cases of anterolateral thigh flaps, 40 cases of pectoralis major muscle flaps, 41 cases of peroneal muscle flaps, of which 21 cases failed. The median operation duration and blood loss were 5.6 hours (range: $3.2-14.4$ hours) and $421.4 \mathrm{ml}$ (range:125-5359 ml), respectively (Table 1-3).

Table 1

Demographic characteristics of patients $(n=632)$ that underwent major surgery for HNC were grouped according to the development of SSI.

\begin{tabular}{|c|c|c|c|c|}
\hline Variable & & SSI (-) & SSI (+) & $P$ \\
\hline \multirow[t]{2}{*}{ Age (Years) } & $>60(n=132)$ & 113 & 19 & 0.58 \\
\hline & $\leq 60(n=500)$ & 437 & 63 & \\
\hline \multirow[t]{2}{*}{ Sex } & Male $(n=493)$ & 433 & 60 & 0.25 \\
\hline & Female $(n=139)$ & 117 & 22 & \\
\hline \multirow[t]{2}{*}{ Smoking } & Yes $(n=298)$ & 248 & 50 & 0.03 \\
\hline & No(n = 334) & 202 & 32 & \\
\hline \multirow[t]{2}{*}{ Drinking } & Yes $(n=252)$ & 218 & 34 & 0.75 \\
\hline & No(n= 380) & 332 & 48 & \\
\hline \multirow[t]{2}{*}{ Diabetes mellitus } & Yes(n = 126) & 94 & 32 & $<0.001$ \\
\hline & No(n= 506) & 456 & 50 & \\
\hline \multirow[t]{2}{*}{ Hypertension } & Yes(n = 112) & 100 & 12 & 0.43 \\
\hline & No(n = 520) & 450 & 70 & \\
\hline \multirow[t]{2}{*}{ Hyperlipidemia } & $\operatorname{Yes}(n=16)$ & 13 & 3 & 0.49 \\
\hline & $\mathrm{No}(\mathrm{n}=616)$ & 538 & 78 & \\
\hline
\end{tabular}


Table 2

Preoperative characteristics of HNC patients $(n=632)$ that underwent major surgery were grouped according to the development of SSI.

\begin{tabular}{|c|c|c|c|c|}
\hline Variable & & SSI $(-)$ & SSI (+) & $P$ \\
\hline Previous radiotherapy & Yes $(n=35)$ & 20 & 15 & $<0.001$ \\
\hline & $\mathrm{No}(\mathrm{n}=597)$ & 530 & 67 & \\
\hline Previous chemotherapy & $\operatorname{Yes}(n=22)$ & 15 & 7 & 0.007 \\
\hline & $\mathrm{No}(\mathrm{n}=610)$ & 535 & 75 & \\
\hline Preoperative hospital stays(days) & $>5(n=186)$ & 153 & 33 & 0.02 \\
\hline & $\leq 5(n=446)$ & 397 & 49 & \\
\hline WBC count & $\operatorname{Normal}(n=467)$ & 405 & 62 & 0.02 \\
\hline & $\operatorname{High}(n=106)$ & 99 & 7 & \\
\hline & $\operatorname{Low}(n=59)$ & 46 & 13 & \\
\hline Albumin count & $\operatorname{Normal}(n=478)$ & 424 & 54 & 0.02 \\
\hline & $\operatorname{High}(\mathrm{n}=18)$ & 17 & 1 & \\
\hline & $\operatorname{Low}(n=136)$ & 109 & 27 & \\
\hline Tumor recurrence & Yes $(n=64)$ & 43 & 21 & $<0.001$ \\
\hline & $\mathrm{No}(\mathrm{n}=568)$ & 507 & 61 & \\
\hline Clinical stage & $I-I I(n=340)$ & 310 & 30 & 0.003 \\
\hline & III-IV(n = 292) & 240 & 52 & \\
\hline Tumor site & Tongue $(n=265)$ & 235 & 30 & 0.005 \\
\hline & $\operatorname{Gingiva}(n=40)$ & 37 & 3 & \\
\hline & Buccal $(n=66)$ & 62 & 4 & \\
\hline & Floor of mouth $(n=80)$ & 58 & 22 & \\
\hline & Jawbone $(n=42)$ & 38 & 4 & \\
\hline & $\operatorname{Lips}(n=22)$ & 20 & 2 & \\
\hline & Palate $(n=40)$ & 37 & 3 & \\
\hline & Retromolar region $(\mathrm{n}=35)$ & 27 & 8 & \\
\hline & Submandibular $(\mathrm{n}=27)$ & 23 & 4 & \\
\hline
\end{tabular}

*Others Includes maxillary sinus, parotid gland, temporal bone, and neck skin. 


\begin{tabular}{|lllll|}
\hline Variable & & SSI $(-)$ & SSI (+) & $P$ \\
\hline & Oropharynx $(\mathrm{n}=9)$ & 7 & 2 & \\
\hline Others* $(\mathrm{n}=6)$ & 6 & 0 & \\
\hline ASA grade & $\mathrm{III}(\mathrm{n}=342)$ & 320 & 22 & $<0.001$ \\
\hline $\mathrm{IIIIV}(\mathrm{n}=290)$ & 230 & 60 & \\
\hline *Others Includes maxillary sinus, parotid gland, temporal bone, and neck skin. & \\
\hline
\end{tabular}


Table 3

Perioperative and postoperative characteristics of HNC patients $(n=632)$ that underwent major surgery were grouped according to the development of SSI.

\begin{tabular}{|c|c|c|c|c|}
\hline \multicolumn{2}{|l|}{ Variable } & \multirow{2}{*}{$\begin{array}{l}\text { SSI (-) } \\
119\end{array}$} & \multirow{2}{*}{$\begin{array}{l}\text { SSI (+) } \\
5\end{array}$} & \multirow{2}{*}{$\begin{array}{l}P \\
<0.001\end{array}$} \\
\hline Neck dissection & No(n=124) & & & \\
\hline & Selective $(n=373)$ & 324 & 49 & \\
\hline & $\operatorname{Modified}(n=45)$ & 39 & 6 & \\
\hline & $\operatorname{Radical}(n=43)$ & 35 & 8 & \\
\hline & Bilateral $(n=47)$ & 32 & 15 & \\
\hline \multirow[t]{3}{*}{ Airway management } & Tracheotomy $(n=208)$ & 166 & 42 & $<0.001$ \\
\hline & intubation(n = 332) & 300 & 32 & \\
\hline & No(n = 92) & 84 & 8 & \\
\hline \multirow[t]{2}{*}{ Blood transfusion } & Yes(n = 158) & 138 & 20 & 0.89 \\
\hline & No $(n=474)$ & 412 & 62 & \\
\hline \multirow[t]{2}{*}{ Free flap repair } & Yes $(n=421)$ & 379 & 42 & 0.001 \\
\hline & No(n= 211) & 171 & 40 & \\
\hline \multirow[t]{2}{*}{ Plate reconstruction } & Yes $(n=467)$ & 397 & 70 & 0.01 \\
\hline & No(n = 165) & 153 & 12 & \\
\hline \multirow[t]{2}{*}{ Surgical duration(hr.) } & $>6(n=289)$ & 234 & 55 & $<0.001$ \\
\hline & $\leq 6(n=343)$ & 316 & 27 & \\
\hline \multirow[t]{2}{*}{$\mathrm{EBL}(\mathrm{ml})$} & $>600(n=252)$ & 210 & 42 & 0.02 \\
\hline & $\leq 600(n=380)$ & 340 & 40 & \\
\hline \multirow[t]{2}{*}{ Flap failure } & $\operatorname{Yes}\left(n=21^{\star}\right)$ & 9 & 12 & $<0.001$ \\
\hline & $\mathrm{No}(\mathrm{n}=400)$ & 346 & 54 & \\
\hline \multirow[t]{2}{*}{ Post-surgical hyperglycemia } & Yes $(n=137)$ & 111 & 26 & 0.001 \\
\hline & No $(n=495)$ & 439 & 56 & \\
\hline \multirow[t]{2}{*}{ Oral-neck communication } & Yes $(n=472)$ & 419 & 53 & 0.02 \\
\hline & $\mathrm{No}(\mathrm{n}=160)$ & 131 & 29 & \\
\hline
\end{tabular}

2. Univariate analysis of SSI risk factors in HNC patients. 
Several demographic and clinical factors influencing SSI were selected for univariate analysis. The patients-related demographic characteristics are shown in Table 1. We found that the incidence of SSI was higher in patients with diabetes $(* \star * P<0.001)$. These results also show that patients with a history of smoking are more likely to develop SSI $(* P<0.05)$.

The preoperative characteristics of HNC patients are listed in Table 2. We observed a statistically significant correlation between SSI and previous radiotherapy ( $\star \star \star ~ P<0.001$ ), previous chemotherapy ( $\star \star$ $P<0.01)$, preoperative hospital stays $\left({ }^{\star} P<0.05\right)$, WBC count $(* P<0.05)$, albumin count $(* P<0.05)$, tumor

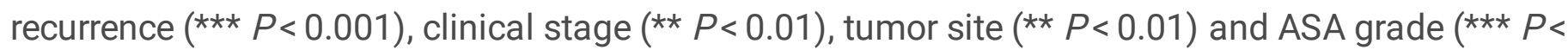
0.001).

The surgery-related characteristics are shown in Table 3. We observed a statistically significant correlation between SSI and neck dissection ( $* \star * P<0.001$ ), airway management $(* \star \star P<0.001)$, free flap repair ( ${ }^{\star *} P=0.001$ ), plate reconstruction ( $\left.{ }^{\prime} P=0.01\right)$, surgical duration ( $\left.* \star \star * P<0.001\right), \operatorname{EBL}(* \star \star P=0.02)$, flap failure ( $\left.{ }^{* \star} P<0.001\right)$, post-surgical hyperglycemia ( $\left.* * P=0.001\right)$ and oral-neck communication ( $*=$ 0.02).

\section{Multivariate logistic regression analysis of risk factors of SSI in HNC patients.}

A Multivariate logistic regression analysis was applied to analyze the relationship between SSI and the significant factors which has been identified in prior univariate analyses (Shown in Table 4). In this model, diabetes mellitus $(\mathrm{OR}=3.212,95 \% \mathrm{Cl}[2.221-4.184]$, $\star \star \star ~ P<0.001)$ and flap failure $(\mathrm{OR}=4.562$, 95\% Cl [3.123-5.782], *** $P<0.001)$ were significant independent predictors of SSI. In addition, tumor site (floor of mouth) (OR=4.239, 95\% Cl [2.167-5.942], * $P=0.021)$, Neck dissection (bilateral) $(\mathrm{OR}=3.286$, $95 \% \mathrm{Cl}[1.803-4.578]$, * $P=0.014)$ and previous radiotherapy (OR $=2.983,95 \% \mathrm{Cl}[2.123-3.763], * P=$ 0.024 ) significantly increased the probability of SSI.

Table 4

Forward stepwise multivariate logistic regression analysis of independent risk factors for SSI in patients $(n=632)$ who underwent major surgery for HNC.

\begin{tabular}{|lll|}
\hline Risk factor & OR $(95 \% \mathrm{Cl})$ & $P$ \\
\hline Diabetes mellitus & $3.212(2.221-4.184)$ & $<0.001$ \\
\hline Previous radiotherapy & $2.983(2.123-3.763)$ & 0.024 \\
\hline Tumor location (Floor of mouth) & $4.239(2.167-5.942)$ & 0.021 \\
\hline Neck dissection (Bilateral) & $3.286(1.803-4.578)$ & 0.014 \\
\hline Flap failure & $4.562(3.123-5.782)$ & $<0.001$ \\
\hline
\end{tabular}

\section{Machine Learning.}

Machine-learning methods are particularly suited to predictions based on existing data and can improve the accuracy of prediction over the use of conventional regression models by capturing complex, 
nonlinear relationships in the data[23]. It is widely used in the prediction of clinical outcomes and the evaluation of the weights of prognostic factors. For example, Khitan, et al. applied machine learning to the American kidney data system to predict the adverse outcomes of end-stage renal disease[24]. Xuanchen Zhou, et al. constructed two different machine learning models to investigate features of importance involving $10 \mathrm{~m} 6 \mathrm{~A}$ regulatory genes[25]. Here, for the first time, in order to evaluate the most important characteristics of the demographic and clinical factors which associated with SSI, we used the Neural Network (NN), Random Forest (RF) and Gradient Boost Machinet (GBM) to build predictive models, respectively (Fig. 1. A-C). We found that diabetes mellitus, tumor site and flap failure were consistently ranked the top three of the 26 SSI-related risk factors and were selected as the most prognostically important locus.

\section{SSI increases postoperative hospital stays and flap failure rate.}

Through Mann-Whitney U test, we found that SSI could increase the postoperative hospital stays. Compared with the SSI-negative group, the average hospital stays of the SSI-positive group increased from 7.3 days to 12.4 days. And the results of Pearson's chi-squared test showed that the SSI-positive group $(6 / 59)$ had a higher rate of flap failure, compared with the SSI-negative group (15/362). The detail of the results is shown in Table 5.

Table 5

Impact of SSI on length of stay (LOS) and flap fail after surgery of HNC.

\begin{tabular}{|lllll|}
\hline Variable & SSI (-) & & SSI (+) & $P$ \\
\hline length of stay (days) & Median & 7.3 & 12.4 & 0.002 \\
& Mean & 7.5 & 11.9 & \\
& SD & 2.1 & 3.1 & \\
\hline Flap failure & Yes $(\mathrm{n}=21)$ & 15 & $6 *$ & 0.04 \\
\hline No $(\mathrm{n}=400)$ & 347 & 53 & \\
\hline *, The patient's infection appeared before the flap failed. & \\
\hline
\end{tabular}

\section{Discussion}

HNC always requires surgery-based comprehensive sequential therapy [26]. However, advances in medical care and the use of antibiotics have not significantly reduced the incidence of SSI in HNC patients after surgery. SSI can prolong hospital stays, increase medical costs and, in severe cases, even lead to death $[2,8]$. Our previous studies have shown that SSI is associated with increased perioperative mortality and poorer OS in HNC patients [9]. In this study, we found that SSI increased the flap failure rate and the length of postoperative hospital stay. Compared with the SSI-negative group, the average hospital stays of the SSI-positive group increased from 7.3 days to 12.4 days (Table 5). Therefore, exploring the 
risk factors for SSI control of postoperative infection can not only reduce the burden on patients and doctors, but also reduce the occurrence of other postoperative complications, and improve the quality of life and survival rate of patients.

Several previous studies have identified diabetes as a risk factor for SSI[11-13, 27]. Through this study, we further confirmed that diabetes is an independent risk factor for SSI. In multivariate logistic regression analysis, patients with diabetes had a more than threefold increased risk of developing SSI compared with those without diabetes $(\mathrm{OR}=3.212)$. After further ranking the importance of the risk factors that may be related to SSI through three models constructed by machine learning, we found that diabetes ranks top in two of the models (Fig. 1A, 1C). These results suggest that diabetes is the one that deserves the most attention of all possible risk factors for SSI. The 2017 CDC guidelines recommend perioperative blood glucose control for the prevention of SSI in patients with or without diabetes, with a target blood glucose level of $<200 \mathrm{mg} / \mathrm{dl}[13,20,28]$. Therefore, for HNC patients with diabetes and other SSI risk factors (such as prior radiotherapy), blood glucose should be strictly controlled within the normal range during the perioperative period to prevent infection and any other complications. At present, it is generally believed that wound infection caused by diabetes is mainly related to microvascular disease and immunosuppression, and interferes with wound healing[13,29,30]. It is worth noting that diabetes is closely related to flap failure[31, 32]. In this study, we found that flap failure is a risk factor for SSI (Table 3 and Table 4), suggesting both diabetes and flap failure may be risk factors of SSI.

Whether prior radiotherapy is a risk factor for SSI is still controversial[12]. Girod DA[27] and Penel N[33] et al. believe that there was no difference in SSI regardless of whether patients received radiotherapy before surgery, while studies by Robbins KT[34] and Hitomi[12] showed that preoperative radiotherapy increases the risk of SSI in HNC patients. In this study, we found a 2.9-fold increase in the odds of SSI in the preoperative radiotherapy group compared to the non-preoperative radiotherapy group $(\mathrm{OR}=2.983)$. Through machine learning, we found that prior radiotherapy ranks the fourth (Fig. 1A). These results suggest that preoperative radiotherapy is an independent risk factor for SSI. It is widely believed that preoperative radiotherapy can reduce collagen deposition and angiogenesis in the process of wound healing by inducing DNA mutations, microvascular damage and soft tissue fibrosis, leading to wound healing problems $[13,35]$. There are also investigations indicating that preoperative radiotherapy may increase the risk of flap failure[36, 37], which may further increase the risk of SSI. Therefore, preoperative radiotherapy should be carefully considered in elderly and frail HNC patients with underlying diseases such as diabetes, especially in patients with squamous cell carcinoma (SCC), given the insensitivity of SCC to radiotherapy and the increased risk of infection and flap crisis caused by radiotherapy.

In terms of surgery-related variables, we found that flap failure, tumor site and neck dissection were independent risk factors for SSI (Table 3, Table 4). Especially when the flap failed, or the tumor was located at the floor of the mouth, or bilateral cervical lymph node dissection was selected, the risk of SSI increased by $4.562,4.239$, and 3.286 folds, respectively. The result is consistent with previous studies[5, $11-13,27,38]$. Notably, flap failure and tumor site ranked in the top three among the three machine learning models, which indicates that the probability of SSI is greatly increased in HNC patients with 
tumor located in the floor of the mouth and/or with flap failure. Some possible mechanisms underlying the association of flap failure, tumor site and neck dissection with increased SSI are proposed, as follows: (1) When the tumor involves the floor of the mouth and metastasizes to the cervical lymph nodes, a penetrating defect in the mouth and cervical connection can be created during the removal of the tumor and the dissection of cervical lymph node. During postoperative recovery, saliva and food residues may enter the neck through these gaps and cause infection. (2) In aggressive malignancies, complex three-dimensional defects are often formed during tumor resection and cervical lymph node dissection (especially bilateral neck lymph node dissection), which makes the shape of the flap and the tissue defect incompletely matched. Subsequently, the skin flap shrinks, resulting in the formation of postoperative dead space, which tends to cause fluid accumulation and provide a medium for bacterial growth. (3) Flap failure occurs frequently in the process of flap reconstruction, and reoperation becomes an inevitable choice currently. Multiple operations, increasing operative time, and necrotic flap tissue all increase the risk of postoperative infection. Therefore, for patients with tumor invasion of the floor of the mouth or bilateral cervical lymph node dissection, the wound should be carefully closed and the dead space should be tightly filled to prevent oral and neck traffic in the process of the flap reconstruction. Also, adequate antibiotics are used to prevent infection.

\section{Conclusions}

In conclusion, SSIR of HNC patients undergoing surgery in our hospital was about $12.97 \%$. We have identified that diabetes mellitus, tumor site (floor of mouth), flap failure, preoperative radiotherapy, and neck dissection (bilateral) are risk factors for SSI of HNC. Among them, diabetes mellitus, tumor site (floor of mouth) and flap failure are the three risk factors most closely associated with SSI. However, in our study, some information about patient characteristics might be missed due to observer bias. And there are some unknown and unmeasurable confounders that need to be further measured or explored.

\section{Declarations}

\section{Acknowledgements}

Not applicable.

\section{Author Contribution}

All authors contributed to the study conception and design. Material preparation, data collection and analysis were performed by Chengwen Gan, Yannan Wang, Mengxue Wang, Feiya Zhu, Kai Wang, Yan Tang and Bincan Sun. The first draft of the manuscript was written by Chengwen Gan and Yannan Wang, and all authors commented on previous versions of the manuscript.

\section{Funding}

No funds, grants, or other support was received. 


\section{Conflicts of interest/Competing interests}

The authors have no conflicts of interest to declare that are relevant to the content of this article.

\section{Availability of data and materials}

All the data in the manuscript are available from the corresponding author on reasonable request.

\section{Code availability (software application or custom code)}

Not applicable.

\section{Ethics approval}

This retrospective chart review study involving human participants was in accordance with the ethical standards of the institutional and national research committee and with the 1964 Helsinki Declaration and its later amendments or comparable ethical standards. The study was approved by the Ethics Committee of Second Xiangya Hospital of Central South University.

\section{Consent to participate}

Informed consent included in the study was obtained from all individual participants.

\section{Consent for publication}

Not applicable.

\section{References}

1. Son HJ, Roh JL, Choi SH, Nam SY, Kim SY: Nutritional and hematologic markers as predictors of risk of surgical site infection in patients with head and neck cancer undergoing major oncologic surgery. Head \& neck 2018, 40(3):596-604.

2. Akashi M, Furudoi S, Hashikawa K, Sakakibara A, Hasegawa T, Shigeta T, Minamikawa T, Komori T: Postoperative abnormal response of C-reactive protein as an indicator for infectious complications after oral oncologic surgery with primary reconstruction. Journal of Otolaryngology - Head \& Neck Surgery 2015, 44(1):1-5.

3. Cloke DJ, Green JE, Khan AL, Hodgkinson PD, Mclean NR: Factors influencing the development of wound infection following free-flap reconstruction for intra-oral cancer. British Journal of Plastic Surgery 2004, 57(6):556-560.

4. Huberman BA: Risks of wound infection in patients with head and neck cancer : Robbins K, Faurot S, Hanna D, et al. Head Neck Surg 12:143, 1990. Journal of Oral \& Maxillofacial Surgery 1990, 48(11):1240-1241. 
5. Liu SA, Wong YK, Poon CK, Wang CC, Wang CP, Tung KC: Risk factors for wound infection after surgery in primary oral cavity cancer patients. Laryngoscope 2010, 117(1):166-171.

6. Simons JP, Johnson JT, Yu VL, Vickers RM, Gooding WE, Myers EN, Pou AM, Wagner RL, Grandis JR: The Role of Topical Antibiotic Prophylaxis in Patients Undergoing Contaminated Head and Neck Surgery With Flap Reconstruction \&dagger. 2001, 111(2):329-335.

7. Lotfi CJ, Cavalcanti RDC, Silva AMCE, Latorre MdRDdO, Kowalski LP: Risk factors for surgical-site infections in head and neck cancer surgery. Otolaryngol Head Neck Surg 2008, 138(1):74-80.

8. Jun, Sato, Jun, Goto, Ayako, Harahashi, Tsubasa, Murata, Hironobu, Hata: Oral health care reduces the risk of postoperative surgical site infection in inpatients with oral squamous cell carcinoma. Supportive Care in Cancer 2011.

9. Wang Y, Wang M, Tang Y, Sun B, Wang K, Zhu F: Perioperative mortality of head and neck cancers. BMC Cancer 2021, 21(1):1-9.

10. Cunha TFS, Melancia TAS, Ribeiro CMZF, Brito JAAD, Miguel SSA, Casal DAAEBod: Risk factors for surgical site infection in cervico-facial oncological surgery. Journal of Cranio-Maxillofacial Surgery 2012, 40(5):443-448.

11. Dong HL, Sang YK, Nam SY, Choi SH, Choi JW, Roh JL: Risk factors of surgical site infection in patients undergoing major oncological surgery for head and neck cancer. Oral Oncology 2011, 47(6):528-531.

12. Ogihara $\mathrm{H}$, Takeuchi $\mathrm{K}$, Majima Y: Risk factors of postoperative infection in head and neck surgery. Auris Nasus Larynx 2009, 36(4):457-460.

13. Shi M, Han Z, Qin L, Su M, Liu Y, Li M, Cheng L, Huang X, Sun Z: Risk factors for surgical site infection after major oral oncological surgery: the experience of a tertiary referral hospital in China. Journal of International Medical Research, 48(8).

14. C.-J., Busch, R., Knecht, A., Münscher, J., Matern, C., Dalchow: Postoperative antibiotic prophylaxis in clean-contaminated head and neck oncologic surgery: a retrospective cohort study. European Archives of Oto-Rhino-Laryngology 2016, 273(9):2805-2811.

15. Fusconi M, Gallo A, Vitiello C, Pagliuca G, Pulice G, de Vincentiis M: Clean-Contaminated Neck Surgery: Risk of Infection by Intrinsic and Extrinsic Factors. Archives of otolaryngology--head \& neck surgery 2006, 132(9):953.

16. Coskun H, Erisen L, Basut O: Factors affecting wound infection rates in head and neck surgery. Otolaryngology-Head and Neck Surgery 2000, 123(3):328-333.

17. Sepehr A, Santos BJG, Chou C, Karimi K, Devcic Z, Oels S, Armstrong WB: Antibiotics in head and neck surgery in the setting of malnutrition, tracheotomy, and diabetes. The Laryngoscope 2009, 119(3):549-553.

18. Raikundalia MD, Fang CH, Spinazzi EF, Vazquez A, Park RC, Baredes S, Eloy JA: Impact of diabetes mellitus on head and neck cancer patients undergoing surgery. Otolaryngology-Head and Neck Surgery 2016, 154(2):294-299. 
19. Belusic-Gobic M, Zubovic A, Cerovic R, Dekanic A, Marzic D, Zamolo G: Multivariate analysis of risk factors for postoperative wound infection following oral and oropharyngeal cancer surgery. Journal of Cranio-Maxillofacial Surgery 2018, 46(1):135-141.

20. Berríos-Torres SI, Umscheid CA, Bratzler DW, Leas B, Stone EC, Kelz RR, Reinke CE, Morgan S, Solomkin JS, Mazuski JE: Centers for Disease Control and Prevention Guideline for the Prevention of Surgical Site Infection, 2017. Jama Surgery 2017.

21. Mangram AJ, Horan TC, Pearson ML, Silver C, Jarvis WR: Guideline for Prevention of Surgical Site Infection, 1999. American Journal of Infection Control 1999, 27(2).

22. Tsai MH, Chuang HC, Lin YT, Lu H, Chen WC, Fang FM, Chien CY: Clinical impact of albumin in advanced head and neck cancer patients with free flap reconstruction-a retrospective study. other 2018,6 .

23. Chen JH, Asch SM: Machine Learning and Prediction in Medicine - Beyond the Peak of Inflated Expectations. N Engl J Med 2017, 376(26):2507-2509.

24. Khitan Z, Jacob AD, Balentine C, Jacob AN, Sanabria JR, Shapiro Jl: Predicting Adverse Outcomes in End Stage Renal Disease: Machine Learning Applied to the United States Renal Data System. Marshall Journal of Medicine 2018, 4(4):75.

25. Zhou X, Han J, Zhen X, Liu Y, Cui Z, Yue Z, Ding L, Xu S: Analysis of Genetic Alteration Signatures and Prognostic Values of m6A Regulatory Genes in Head and Neck Squamous Cell Carcinoma. Front Oncol 2020, 10:718.

26. Dort JC, Farwell DG, Findlay M, Huber GF, Kerr P, Shea-Budgell MA, Simon C, Uppington J, Zygun D, Ljungqvist O: Optimal perioperative care in major head and neck cancer surgery with free flap reconstruction: a consensus review and recommendations from the enhanced recovery after surgery society. JAMA otolaryngology-head \& neck surgery 2017, 143(3):292-303.

27. Girod DA, Mcculloch TM, Tsue TT, Weymuller EA: Risk factors for complications in cleancontaminated head and neck surgical procedures. Head \& Neck 1995, 17(1).

28. Update to the Centers for Disease Control and Prevention and the Healthcare Infection Control Practices Advisory Committee Guideline for the Prevention of Surgical Site Infection (2017): A summary, review, and strategies for implementation. American Journal of Infection Control 2018:S0196655318300634.

29. Jeffcoate WJ, Price P, Harding KG: Wound healing and treatments for people with diabetic foot ulcers. Diabetes/metabolism Research \& Reviews 2004, 20(Supplement 1):0-0.

30. Knapp, Sylvia: Diabetes and infection: is there a link?-A mini-review. Gerontology 2013, 59(2):99-104.

31. Cooley BC, Hanel DP, Anderson RB, Foster MD, Gould JS: The influence of diabetes on free flap transfer: I. Flap survival and microvascular healing. Annals of Plastic Surgery 1992, 29(1):58-64.

32. Rosado P, Cheng HT, Wu CM, Wei FC, Eisele DW: Influence of diabetes mellitus on postoperative complications and failure in head and neck free flap reconstruction: A systematic review and metaanalysis. Head \& Neck 2015, 37(4):615-618. 
33. Previous chemotherapy as a predictor of wound infections in nonmajor head and neck surgery: Results of a prospective study. Head \& Neck 2004, 26(6):513.

34. Robbins KT, Favrot S, Hanna D, Cole R: Risk of Wound Infection in Patients With Head and Neck Cancer. Head \& Neck 1990, 12(2):143-148.

35. Dormand EL, Banwell PE, Goodacre TE: Radiotherapy and wound healing. International Wound Journal 2010, 2(2):112-127.

36. Na KM, Kim JW, Lee HJ, Kim CS, Lee SH: Evaluation of the Pectoralis Major Myocutaneous Flap for Oral and Maxillofacial Reconstructive Surgery. Maxillofacial Plastic \& Reconstructive Surgery 2013, $35(5)$.

37. Pradyumna, Herle, Lipi, Shukla, Wayne, A., Morrison, Ramin, Shayan: Preoperative radiation and free flap outcomes for head and neck reconstruction: a systematic review and meta-analysis. Anz Journal of Surgery 2014, 85(3):121-127.

38. Hideo S, Kouji O, Masaaki T: Risk factors for postoperative complications following oral surgery. Journal of Applied Oral Science Revista Fob 2015, 23(4):419-423.

\section{Figures}
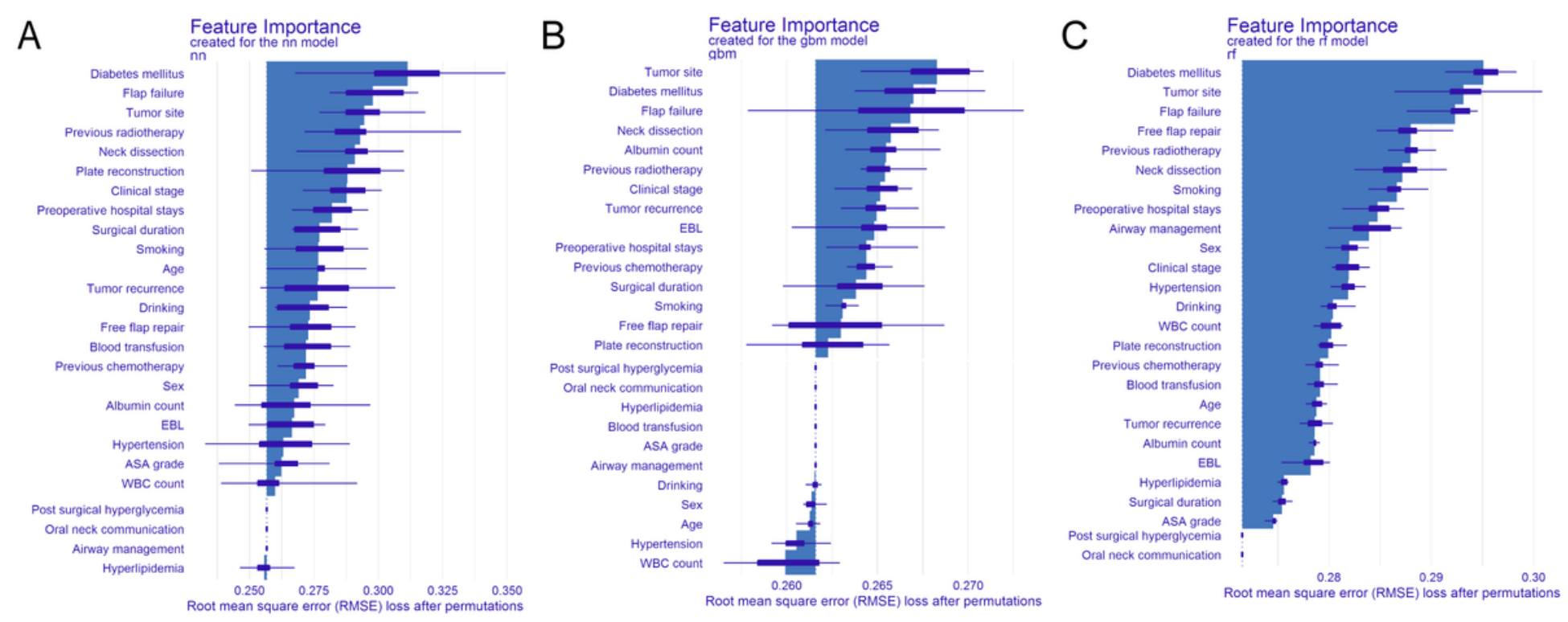

\section{Figure 1}

The correlation between SSI and demographic or clinical parameters of HNC patients. Rank chart for the 26 SSI-related risk factors by (A) NN, (B) RF, and (C) GBM. 